\title{
EGFR inhibition enhances the antitumor efficacy of a selective BRAF V600E inhibitor in thyroid cancer cell lines
}

\author{
YONGSHENG JIA $^{1^{*}}$, CUICUI ZHANG ${ }^{2 *}$, CHUANXIANG HU ${ }^{3}$, YANG YU ${ }^{1}$, \\ XIANGQIAN ZHENG ${ }^{2}$, YIGONG $\mathrm{LI}^{1}$ and MING GAO ${ }^{1}$
}

${ }^{1}$ Thyroid and Neck Department; ${ }^{2}$ Department of Thoracic Oncology, Tianjin Medical University Cancer Institute and Hospital,
National Clinical Research Center for Cancer; ${ }^{3}$ Key Laboratory of Cancer Prevention and Therapy, Tianjin 300060, P.R. China

Received June 7, 2017; Accepted December 8, 2017

DOI: $10.3892 / \mathrm{ol} .2018 .8093$

\begin{abstract}
BRAF V600E is the most common genetic alteration in thyroid cancer and is indicative of a relatively poor prognosis. A selective inhibitor of BRAF V600E has been proposed as a novel treatment for patients with thyroid cancer exhibiting BRAF V600E mutations. However, this inhibitor has demonstrated a limited therapeutic effect. In the present study, possible adaptive mechanisms of resistance of thyroid cancer cells to the specific BRAF V600E inhibitor, PLX4032, were investigated. MTT assays were performed to determine the anti-proliferative efficiencies and half maximal inhibitory concentration $\left(\mathrm{IC}_{50}\right)$ of inhibitory treatments. The level of phosphorylated ERK was used to evaluate the activity of the mitogen assisted protein kinase (MAPK) pathway. Flow cytometry was performed to evaluate the rate of apoptosis. The $\mathrm{IC}_{50}$ measurements of PLX4032 in K1 and BCPAP cells were 0.550 and $1.772 \mu \mathrm{M}$, respectively. Co-treatment with an endothelial growth factor receptor (EGFR) inhibitor decreased the $\mathrm{IC}_{50}$ of PLX4032 to $0.206 \mu \mathrm{M}$, and prolonged the inhibitory effect of PLX4032 in K1 cells. In cells treated with PLX4032 alone, the MAPK pathway was reactivated after $24 \mathrm{~h}$. However, the addition of an EGFR inhibitor suppressed this reactivation and increased the rate of apoptosis. In summary, the present study demonstrated that thyroid cancer harboring the BRAF V600E mutation was resistant to a selective BRAF inhibitor due to reactivation of the MAPK pathway. Co-treatment with an EGFR inhibitor increased antitumor efficacy and suppressed resistance to the BRAF V600E inhibitor.
\end{abstract}

Correspondence to: Professor Ming Gao, Thyroid and Neck Department, Tianjin Medical University Cancer Institute and Hospital, National Clinical Research Center for Cancer, 24 Huanhuxi Road, Tiyuanbei, Hexi, Tianjin 300060, P.R. China

E-mail: thyroidandneck@163.com

*Contributed equally

Key words: endothelial growth factor receptor, BRAF V600E, mitogen assisted protein kinase, selective inhibitor, inhibition resistance

\section{Introduction}

The incidence of thyroid cancer has rapidly increased over the past few years and thyroid cancer is now the fifth most common cancer type diagnosed in women in the USA $(1,2)$. Papillary thyroid cancer (PTC) accounts for $>80 \%$ of thyroid tumors and is associated with a relatively favorable prognosis subsequent to surgical treatment. However, PTC tumors that are difficult to resect and those that metastasize remain a challenge to treat with long-term success (3-5). Examples of such challenging cases include recurrent thyroid cancer and anaplastic thyroid cancer (ATC) (6). It has been reported that recurrence is experienced in $20-30 \%$ of patients with thyroid cancer within the first 20 years post-surgery (7). Radioactive iodine and thyrotropin-suppressive therapies are used to treat these patients; however, persistent metastasis and dedifferentiation despite these treatments associate them with poor prognoses $(4,5)$. The 10 -year survival rate for patients with recurrent disease is only $10 \%$, and this value has remained unchanged for numerous years due to the limited progress in the available treatments for recurrent thyroid cancer (8).

BRAF mutations have been identified in a variety of human cancer types, including thyroid cancer, malignant melanoma, ovarian tumors and colorectal cancer (CRC) $(9,10)$. Over 40 BRAF mutations have been reported, the most commonly reported being BRAF V600E, which results from a thymine-to-adenosine transformation at position 1799 in exon 15 , causing a valine-to-glutamate substitution at residue 600 in the peptide (11). The activity of the BRAF V600E protein is 10 -fold greater than that of the wild-type protein and cannot be regulated appropriately (12). The resulting continuous activation of BRAF V600E activates the mitogen assisted protein kinase (MAPK) signaling pathway and promotes tumor progression (12).

The BRAF V600E mutation occurs in $29-83 \%$ cases of PTC, the most common subtype of thyroid cancer, and $24 \%$ cases of ATC, the most aggressive and lethal subtype of thyroid cancer (13-15). In addition to acting as a biomarker for diagnosis, the BRAF V600E expression is associated with aggressive and iodine-resistant phenotypes of thyroid cancer (14). It has been reported that thyroid cancers harboring the BRAF V600E mutation tend to exhibit other factors indicative of a 
poor prognosis, including extra-thyroidal extension, lymph node metastasis, advanced stage, iodine-131 resistance, recurrent disease and distant metastasis (16-21). Even in papillary thyroid microcarcinoma (with diameters $<1 \mathrm{~cm}$ ), the BRAF V600E mutation is associated with extra-thyroidal extension and lymph node metastasis $(22,23)$.

The BRAF V600E protein has been investigated as a therapeutic target in a number of studies and various BRAF V600E inhibitors have been identified (24-26). Sorafenib is a first-generation BRAF V600E inhibitor. However, the mechanism by which the effect of sorafenib is mediated remains unclear due to its ability to inhibit multiple kinases $(27,28)$. Vemurafenib and dabrafenib are selective BRAF V600E inhibitors, which have demonstrated therapeutic activity in phase 1 and 2 clinical trials in patients with BRAF V600E-mutation-induced metastatic melanoma, and they have been approved by the Food and Drug Administration (29). However, these inhibitors are unable to efficiently suppress the progression of other types of cancer and resistance to the inhibitors developed within 6-7 months, even in melanoma $(30,31)$. In CRC, endothelial growth factor receptor (EGFR)-mediated re-proliferation serves an essential role in the resistance to BRAF inhibition (32). It has been reported that overexpression of EGFR results in constitutive activation of the MAPK signaling pathway and promotes cancer cell proliferation, even during treatment with selective BRAF V600E inhibitors (32). In the present study, BRAF V600E was inhibited and downregulation of EGFR was induced in PTC cell lines to determine whether this combined strategy was able to efficiently block cancer cell proliferation, and if it may be a potential novel treatment for thyroid cancer.

\section{Materials and methods}

Cell lines and reagents. The $\mathrm{K} 1$ and BCPAP cell lines were purchased from Sigma-Aldrich (Merck KGaA Darmstadt, Germany). K1 and BCPAP are papillary thyroid cancer cell lines, and K1 cells are a derivative of the GLAG-66 cell line (33). Both cell lines were passaged for $<3$ months from stocks generated from the first or second passage of the original cells. The mutation status of these cell lines is reported in Table I. BCPAP cells were maintained in Dulbecco's modified Eagle medium with $10 \%$ fetal bovine serum (FBS), and K1 cells were maintained in RPMI-1640 supplemented with $10 \%$ FBS. The cells were maintained at $37^{\circ} \mathrm{C}$ in a humidified incubator with $5 \%$ carbon dioxide. The BRAF V600E-selective inhibitor PLX4032 was obtained from Plexxikon, Inc. (Berkeley, CA, USA) and the EGFR-selective inhibitor, gefitinib, was obtained from Roche Diagnostics (Basel, Switzerland). Inhibitors were dissolved in DMSO and the stock solutions were stored at $-20^{\circ} \mathrm{C}$.

Cellular proliferation assays. Proliferation of K1 and BCPAP cells was evaluated using the MTT assay (Sigma-Aldrich; Merck KGaA). Cells were plated in 96-well microtiter plates at a density of $3 \times 10^{3}$ cells/well in a volume of $180 \mu 1$ DMEM with FBS. PLX4032 with or without gefitinib was diluted in media containing $1 \%$ DMSO at $10 \mathrm{X}$ the final assay concentrations (PLX4032: 0.01, 0.03, 0.1,0.3, 1 and $3 \mu \mathrm{M}$; gefitinib: $0.125 \mu \mathrm{M}$ ). After $24 \mathrm{~h}$ of culture, $20 \mu \mathrm{l}$ each drug dilution was added in triplicate to separate wells. Cells were assayed for proliferation
Table I. Basic information and genetic profiles of the cell lines.

\begin{tabular}{lccc}
\hline Cell line & Subtype & BRAF variation & EGFR variation \\
\hline K1 & PTC & GTG-GAG & Wild-type \\
BCPAP & PTC & GTG-GAG & CAG-CAA \\
\hline
\end{tabular}

EGFR, endothelial growth factor receptor; PTC, papillary thyroid cancer.

at 24, 48, 72, 96 and 120-h time points. The percentage of inhibition was calculated using the following formula: 100-(mean absorbance of experimental wells/mean absorbance of control wells) $x 100$. The half maximal inhibitory concentration $\left(\mathrm{IC}_{50}\right)$ values were determined by calculating the regression of plots produced from the logarithms of concentration vs. percentage inhibition, using XLfit software (version 4.2; ID Business Solutions Ltd., Guildford, UK).

Western blot analysis. Cells were seeded at 70-75\% confluence in 6-well plates, 1 day prior to drug treatment. Cells were cultured at the aforementioned drug concentrations and times at $37^{\circ} \mathrm{C}$ with $5 \% \mathrm{CO}_{2}$, and were harvested and lysed in $1 \mathrm{X}$ cell lysis buffer (Cell Signaling Technology, Inc., Danvers, MA, USA). After a 20-min incubation on ice, the lysates were centrifuged at $12,000 \mathrm{x} \mathrm{g}$ for $15 \mathrm{~min}$ at $4^{\circ} \mathrm{C}$ to clear insoluble debris. The protein concentrations of the lysates were then determined with a BCA kit (Invitrogen; Thermo Fisher Scientific, Inc., Waltham, MA, USA), and equal amounts of total protein from cell lysates and tumor lysates (10 $\mu \mathrm{g}$ for each lane) were resolved on 4-12\% NuPage gradient polyacrylamide gels (Invitrogen; Thermo Fisher Scientific, Inc.) before they were blotted onto polyvinylidene fluoride membrane (GE Healthcare Life Sciences, Little Chalfont, UK). The membranes were first blocked with 5\% dry fat free milk for $1 \mathrm{~h}$ at room temperature and washed twice with Tris-Buffered Saline containing 0.1\% Tween-20 (Affymetrix, Inc.; Thermo Fisher Scientific, Inc.). The blocked membranes were probed with rabbit polyclonal antibodies against human phosphorylated-extracellular regulated kinase (p-ERK1/2) (Cell Signaling Technology, Inc.; cat no. 4370S; dilution, 1:1,000), ERK1/2 (Sigma-Aldrich; Merck KGaA; cat no. M5670; dilution, 1:1,000), $\beta$-actin (cat no. sc-130656; Santa Cruz Biotechnology, Inc., Dallas, TX, USA; dilution, 1:2,000) and incubated for $2 \mathrm{~h}$ at room temperature. Followed by incubation for $1 \mathrm{~h}$ at room temperature with horseradish peroxidase-conjugated goat anti-rabbit IgG secondary antibody (cat no. sc-2004; dilution, 1:5,000; Santa Cruz Biotechnology, Inc.). A chemiluminescent signal was generated using Amersham ECL Plus Western Blotting Detection reagents (GE Healthcare, Chicago, IL, USA) and detected with a Fujifilm LAS-3000 imager (Fujifilm, Tokyo, Japan). The densitometry was performed using Multi Gauge 3.0 software (Fujifilm).

Flow cytometry. Cells were seeded in 6-well plates at $4 \times 10^{5}$ cells/well and incubated for $24 \mathrm{~h}$ prior to treatment with PLX4032 and/or gefitinib. A total of five treatment groups were analyzed: PLX4032 monotreatment for 1 day; PLX4032 monotreatment for 5 days; PLX4032 combined with gefitinib 
A
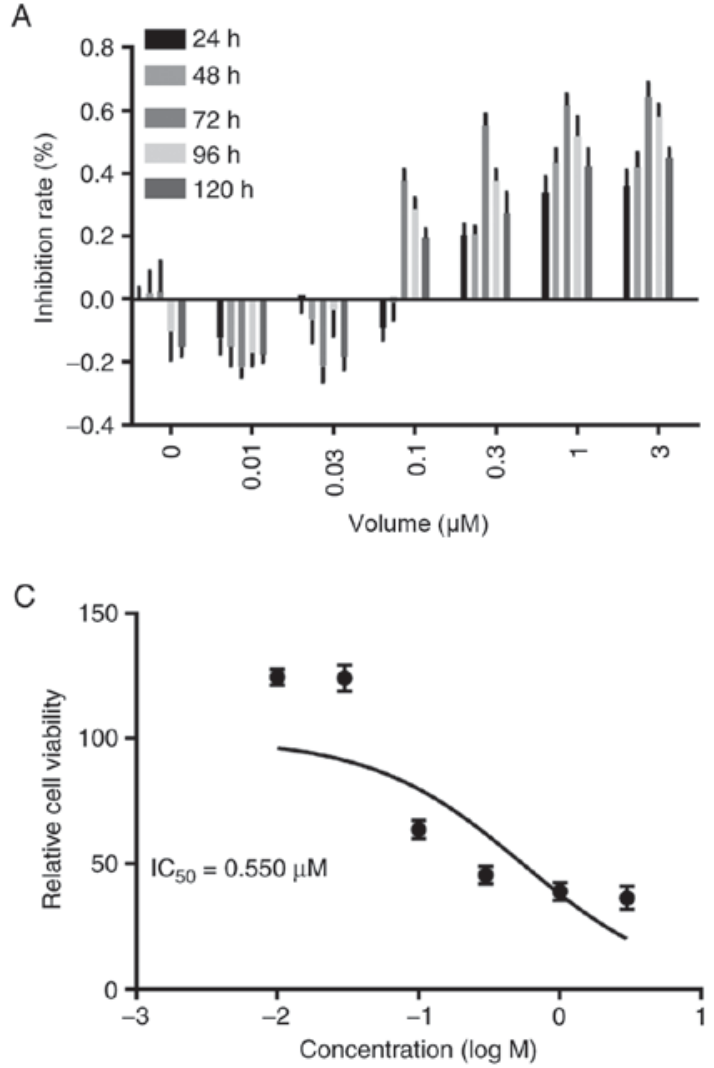

B
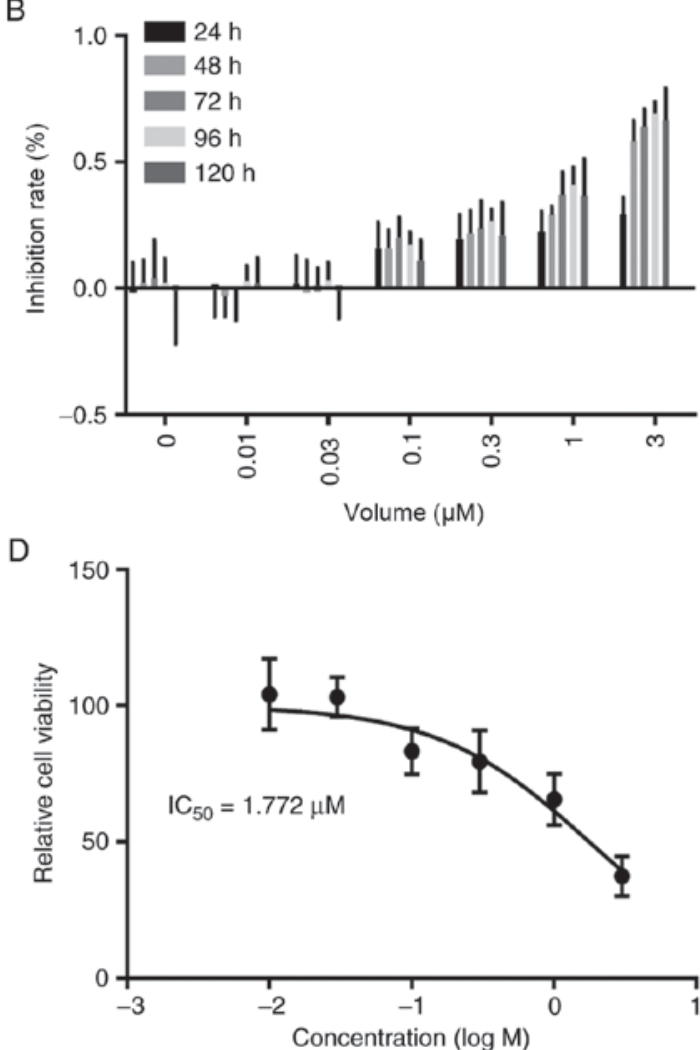

Figure 1. Anti-proliferation efficacy of PLX4032 in K1 and BCPAP cells. K1 and BCPAP cells were treated with PLX4032 at $0.01,0.03,0.1,0.3,1$ or $3 \mu \mathrm{M}$ for 24, 48, 72, 96 or $120 \mathrm{~h}$. Untreated cells served as a control. (A) PLX4032 inhibition rate (\%) in K1 cells. (B) PLX4032 inhibition rate (\%) in BCPAP cells. (C) $\mathrm{IC}_{50}$ of $\mathrm{K} 1$ cells treated with PLX4032 for $72 \mathrm{~h}$. (D) $\mathrm{IC}_{50}$ of BCPAP cells treated with PLX4032 for $72 \mathrm{~h}$. IC ${ }_{50}$, half maximal inhibitory concentration; log $\mathrm{M}, \log$ (inhibitor) vs. normalized response.

for 1 day; and PLX4032 combined with gefitinib for 5 days. The concentrations of PLX4032 and gefitinib were 0.206 and $0.125 \mu \mathrm{M}$, respectively. Untreated cells were used as a control group. Apoptosis was evaluated by measuring the exposure of phosphatidylserine on cell membranes using Annexin V-FITC apoptosis detection kits (Sigma-Aldrich; Merck KGaA). Following the treatments, cell pellets were resuspended in a solution containing $5 \mu \mathrm{g} / \mathrm{ml}$ propidium iodide and $1 \mu \mathrm{g} / \mathrm{ml}$ Annexin V-fluorescein isothiocyanate for $15 \mathrm{~min}$ at room temperature in darkness. Subsequently, the cells were assessed by a flow cytometer equipped with CellQuest 5.1 software (BD Biosciences, Franklin Lakes, NJ, USA).

Statistical methods. GraphPad Prism 7.0 software (GraphPad Software, Inc., La Jolla, CA, USA) was used to analyze all data and the results are presented as the mean \pm standard error. Significant differences were determined by one-way analysis of variance followed by Tukey's post hoc test. $\mathrm{P}<0.05$ was considered to indicate a statistically significant difference.

\section{Results}

Co-treated with gefitinib and PLX4032 had a stronger anti-proliferation efficacy. To evaluate the anti-proliferation efficacy of PLX4032, the $\mathrm{IC}_{50}$ values of PLX4032 were obtained for K1 and BCPAP cells using an MTT assay at different time-points. Both cell lines were most sensitive to PLX4032 at $72 \mathrm{~h}$. The $\mathrm{IC}_{50}$ in $\mathrm{K} 1$ cells $(0.550 \mu \mathrm{M})$ was compared with BCPAP cells $(1.772 \mu \mathrm{M})$ (Fig. 1). It has been reported that the $\mathrm{IC}_{50}$ of gefitinib is $0.125 \mu \mathrm{M}$ for other cancer cell lines (32). The $\mathrm{IC}_{50}$ for PLX4032 in $\mathrm{K} 1$ cells co-treated with gefitinib was determined at the 72 -h time-point. The combination suppressed proliferation more effectively than PLX4032 treatment alone, resulting in a lower $\mathrm{IC}_{50}$ of $0.206 \mu \mathrm{M}$ (Fig. 2).

Reactivation of the MAPK signaling pathway was found in papillary thyroid cancer cell lines. To investigate the mechanism of inhibitor resistance, the activity of the MAPK signaling pathway was examined. ERK is a key enzyme in this pathway; therefore, the phosphorylation of ERK was measured in order to evaluate MAPK pathway activity. K1 and BCPAP cells were treated with PLX4032 (K1: $0.2 \mu \mathrm{M}$; BCPAP: $1.772 \mu \mathrm{M}$ ) for $12 \mathrm{~h}$. Western blot analyses indicated that p-ERK levels were low in the PLX4032-treated groups compared with the control groups, suggesting that MAPK activity was suppressed by PLX4032 (Fig. 3). K1 was more sensitive to PLX4032; therefore K1 was used in the following experiments. Treatment of $\mathrm{K} 1$ cells with varying concentrations $(0,0.01,0.03,0.1,0.3$ and $1 \mu \mathrm{M})$ of PLX4032 demonstrated that this inhibition of MAPK was dose-dependent (Fig. 4). Subsequently, K1 cells were treated with $0.550 \mu \mathrm{M}$ PLX4032 and the p-ERK levels were examined at different time points $(0,6,24$ and $48 \mathrm{~h})$. The lowest level of p-ERK was detected at the $6 \mathrm{~h}$ time-point, after 
Discrepancy inhibition rate in $\mathrm{K} 1$ after $72 \mathrm{~h}$-posttreatment

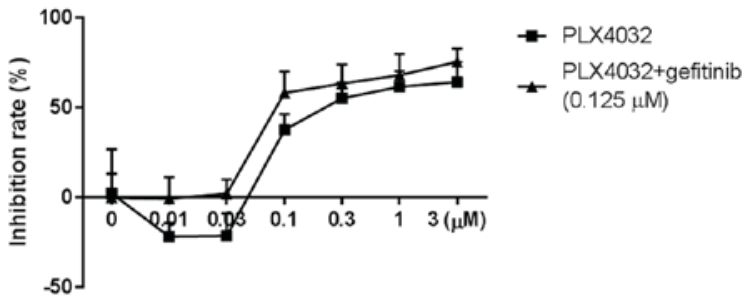

Figure 2. The anti-proliferation efficacy of PLX4032 with or without gefitinib in $\mathrm{K} 1$ cells at $72 \mathrm{~h}$. The $\mathrm{IC}_{50}$ of PLX4032 in the presence of gefitinib $(0.206 \mu \mathrm{M})$ was significantly lower than that of PLX4032 alone $(0.550 \mu \mathrm{M})$ $(\mathrm{P}<0.05)$. $\mathrm{IC}_{50}$, half maximal inhibitory concentration.
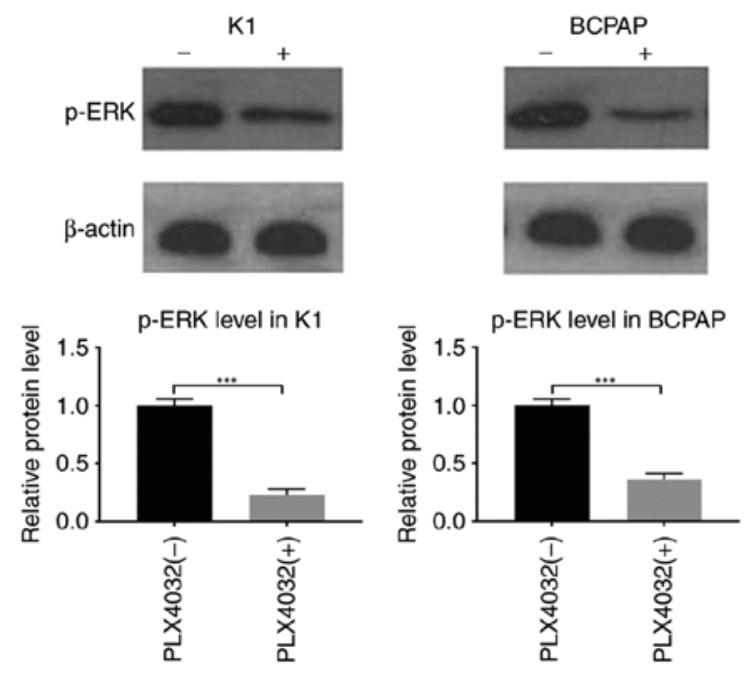

Figure 3. Effects of acute treatment with PLX4032 on the K1 and BCPAP cell lines. p-ERK was used to evaluate MAPK activation. Protein level was quantified relative to $\beta$-actin. Following $12 \mathrm{~h}$ treatment, p-ERK was significantly decreased in $\mathrm{K} 1$ and BCPAP cells $(\mathrm{P}<0.05)$. p-, phosphorylated; ERK, extracellular signal-related kinase; MAPK, mitogen-activated protein kinase. ${ }^{* * * *} \mathrm{P}<0.05$.

which the p-ERK levels increased, indicating reactivation of the MAPK signaling pathway (Fig. 5).

Co-treated with gefitinib and PLX4032 promoted apoptosis. Flow cytometric analysis of apoptosis indicated that apoptosis was elevated in cells cultured with PLX4032 for 1 day compared with cells in the control group. However, apoptosis in the treated group decreased from day 1 to 5 , indicating a decrease in the antitumor activity of PLX4032. Apoptosis of K1 cells treated with PLX4032 and gefitinib was significantly elevated compared with the control group and the PLX4032 monotreatment group $(\mathrm{P}<0.05)$. In the co-treated group, there was no significant difference between the level of apoptosis on days 1 and 5, which indicates continued suppression over time (Fig. 6). Additionally, the combined treatment with an EGFR inhibitor was able to increase the antitumor efficacy of BRAF V600E inhibitors and suppress drug resistance in PTC cells (Fig. 7).

\section{Discussion}

The BRAF V600E mutation has been reported in numerous types of cancer, including thyroid cancer, CRC and

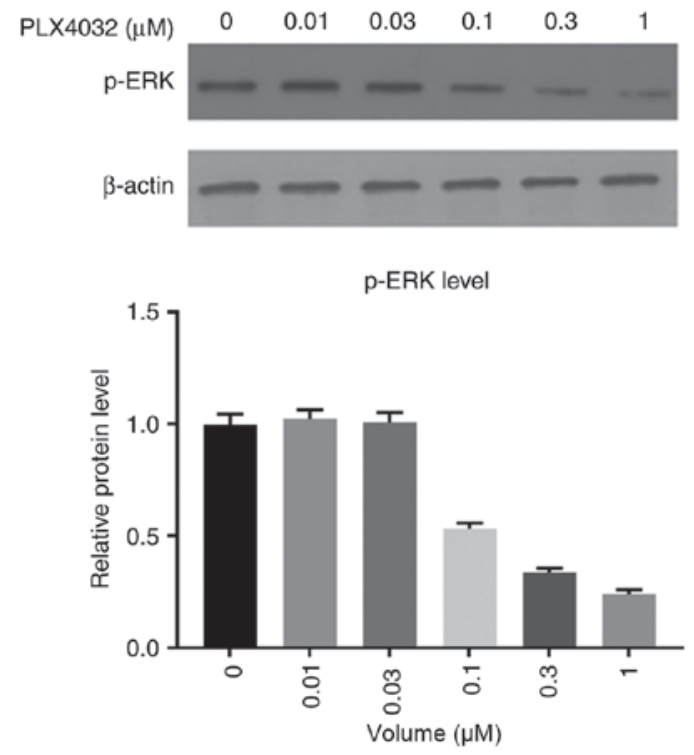

Figure 4. MAPK pathway activation in PLX4032-treated cells. K1 cells were treated with the indicated concentrations of PLX4032 for $12 \mathrm{~h}$. Untreated cells served as a control group. Protein level was quantified relative to $\beta$-actin. PLX4032 significantly p-ERK expression at concentrations greater than $0.1 \mu \mathrm{M}$, and this inhibition was dose-dependent. MAPK, mitogen-activated protein kinase; p-, phosphorylated; ERK, extracellular signal-related kinase.
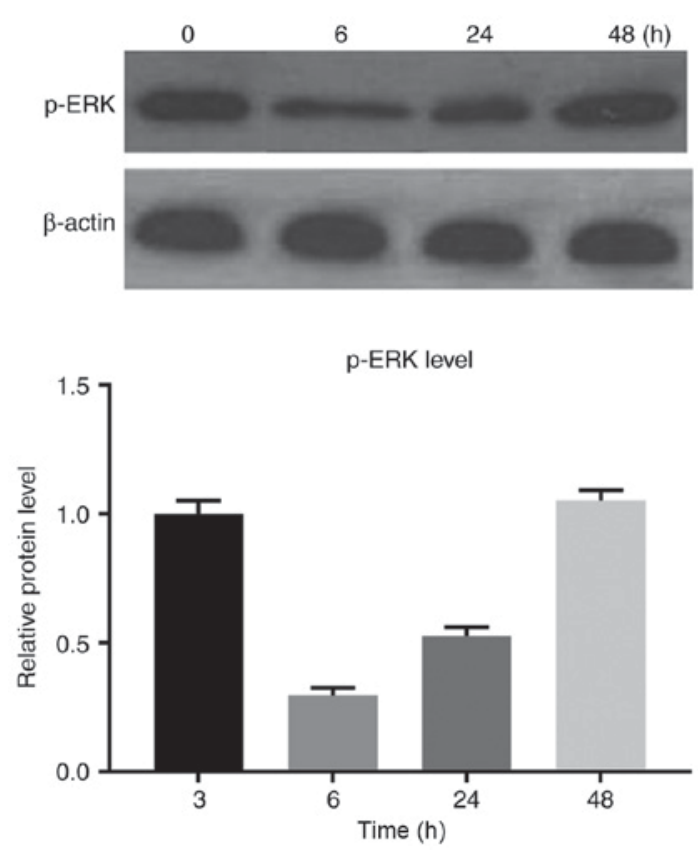

Figure 5. Time-course study of MAPK pathway activation in PLX4032-treated cells. The highest level of inhibition was observed at $6 \mathrm{~h}$, after which the MAPK pathway was reactivated. Untreated cells $(0 \mathrm{~h})$ served as a control. Protein level was quantified relative to $\beta$-actin. MAPK, mitogen-activated protein kinase; p-, phosphorylated; ERK, extracellular signal-related kinase.

melanoma $(9,10)$. BRAF V600E is an oncogene, and serves an important role in tumorigenesis and cancer progression. The protein encoded by BRAF V600E is $>10$-fold more active compared with the wild-type protein and is not regulated by normal feedback mechanisms (12). BRAF V600E can continuously activate the MAPK signaling pathway, thus promoting tumor proliferation, invasion and metastasis (34). BRAF 
A
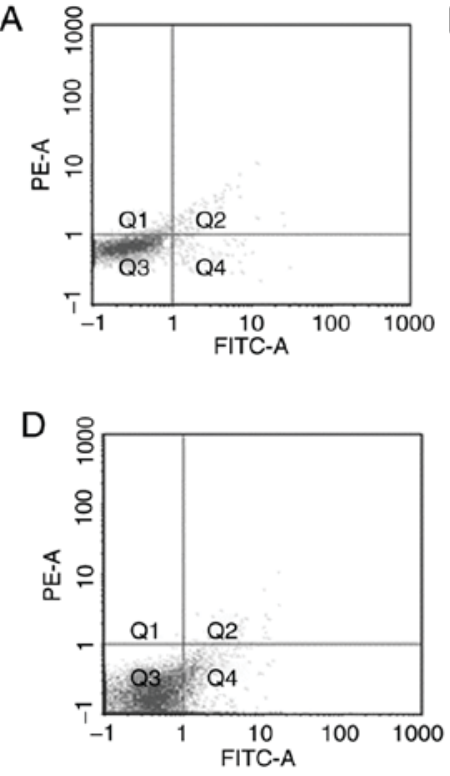

$\mathrm{B}$

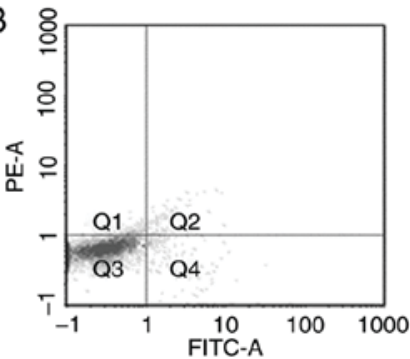

$\mathrm{E}$

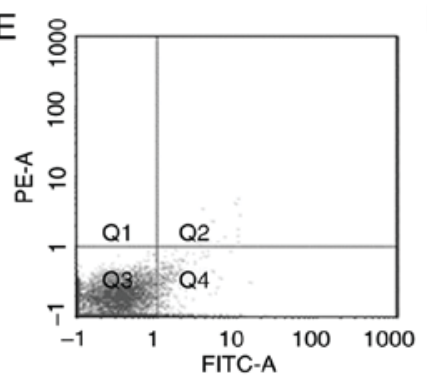

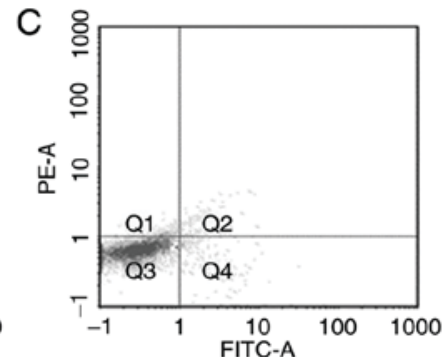

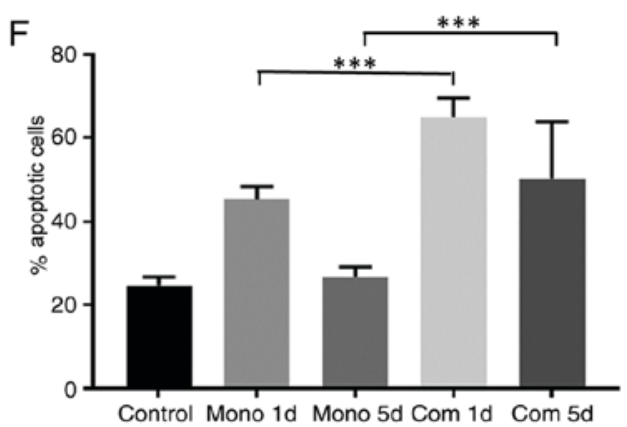

Figure 6. Rate of apoptosis in cells treated with PLX4032 and/or gefitinib. PLX4032-treated K1 cells demonstrated elevated levels of apoptosis compared with control cells after 1 day of treatment $(\mathrm{P}<0.05)$. However, there was no significant difference after 5 days of treatment. The combination of gefitinib and PLX4032 induced apoptosis more effectively than PLX4032 alone ( $<<0.05)$. The treatment groups were as follows: Mono 1d, PLX4032 (0.550 $\mu \mathrm{M})$ treatment for 1 day; Mono 5d: PLX4032 $(0.550 \mu \mathrm{M})$ treatment for 5 days; Com 1d, PLX4032 $(0.206 \mu \mathrm{M})$ combined with gefitinib $(0.125 \mu \mathrm{M})$ treatment for 1 day; Com 5d, PLX4032 $(0.206 \mu \mathrm{M})$ combined with gefitinib $(0.125 \mu \mathrm{M})$ treatment for 5 days. (A) No treatment; (B) PLX4032 monotreatment for 1 day; (C) PLX4032 monotreatment for 5 days; (D) PLX4032 combined with gefitinib for 1 day; (E) PLX4032 combined with gefitinib for 5 days, and (F) quantification of apoptotic rates according to treatment group. PE-A, phycoerythrin-A; FITC-A, fluorescein isothiocyanate; mono, monotreatment; comb, combined treatment. ${ }^{* * *} \mathrm{P}<0.05$.

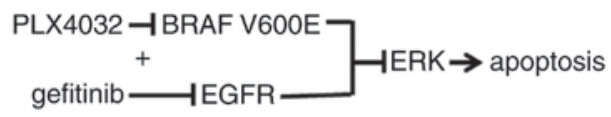

Figure 7. Proposed mechanistic model for the function of BRAF V600E and EGFR in thyroid cancer cell lines. EGFR, endothelial growth factor receptor; ERK, extracellular signal-related kinase.

V600E mutations occur at different rates in different cancer types, but the presence of the mutation consistently indicates poor prognosis $(14,15)$.

BRAF V600E is one of the most common genetic alterations in thyroid cancer. It occurs in $29-83 \%$ of PTCs, which comprise $>80 \%$ of all thyroid tumors (13). PTCs harboring the BRAF V600E mutation have more aggressive clinicopathological features, including extra-thyroidal extension and lymph node metastasis (13-15). Seeing as there are limited therapies for metastatic thyroid cancer, novel treatments are essential to improve disease outcomes for patients exhibiting this mutation. Inhibitors targeting the BRAF V600E protein have been evaluated in clinical trials. However, the inhibitor response depends on the type of cancer $(24,25,30)$. The selective inhibitor PLX4032 has exhibited beneficial therapeutic effects on metastatic melanoma, but no effect on colon or thyroid cancers (32). Numerous mechanisms to account for the resistance of thyroid cancer to BRAF inhibition have been suggested, including the following: Activation of the RAF/MEK/ERK pathway caused by BRAF alternative splicing; activation of the phosphoinositide 3-kinase (PI3K)/AKT serine/threonine kinase (AKT) pathway through hepatocyte growth factor receptor; autocrine neuregulin 1-mediated human epidermal growth factor receptor 3 activation of the PI3K/AKT and RAS/RAF/MEK/ERK pathways; autocrine interleukin-6-mediated activation of the janus kinase/signal transducer and activator of transcription 3 and RAS/RAF/MEK/ERK pathways, and increased autophagy (31,35-37).

In CRC, it has been reported that EGFR overexpression promotes tumor proliferation (32). The present study determined whether PLX4032 combined with the EGFR inhibitor, gefitinib, was able to suppress thyroid cancer cell proliferation. Co-treatment with gefitinib significantly increased the antitumor activity of PLX4032. Frasca et al (38) reported that co-treatment with PLX4032 was able to decrease the $\mathrm{IC}_{50}$ of gefitinib. These data indicate that PLX4032 (vemurafenib) and gefitinib are able to produce synergistic effects. Vemurafenib and gefitinib are safe for use in patients, and therapeutic regimen combining BRAF and MAPK inhibitors may result in greater efficacy and fewer side effects.

To further understand the molecular mechanism of BRAF inhibitor resistance, activity of the MAPK pathway was examined. In thyroid cancer cell lines, the MAPK pathway was suppressed by PLX4032. This inhibition was the most effective after $6 \mathrm{~h}$ of treatment. MAPK activity gradually increased after $6 \mathrm{~h}$, indicating that the pathway was reactivated. Danysh et al (39) reported that treatment of PTC cell lines with a selective BRAF inhibitor for 5 months led to the acquisition of resistance to the inhibitor through a spontaneous KRAS G12D mutation. Thus, cancer cells can acquire short-term and long-term resistance to BRAF inhibition. In the present study, combined treatment with gefitinib and PLX4032 continuously suppressed the MAPK pathway, indicating that EGFR serves an important role in the resistance of cells to BRAF inhibition. 
As MAPK signaling has an established association with apoptosis, the survival of PLX4032-treated thyroid cancer cells was quantified. Flow cytometry demonstrated that PLX4032 treatment initially increased apoptosis, but this effect declined after 5 days of treatment, indicating that the effect of PLX4032 on cell survival was short-term. Combined treatment with gefitinib significantly increased apoptosis and prolonged this effect (Fig. 7).

In conclusion, PTC cells harboring a BRAF V600E mutation may become resistant to selective BRAF inhibition through reactivation of the EGFR/MAPK pathway. Combined treatment with an EGFR inhibitor is able to increase the antitumor efficacy of BRAF V600E inhibitors and suppress drug resistance in PTC cells.

\section{Acknowledgements}

Not applicable.

\section{Funding}

No funding was received.

\section{Availability of data and materials}

All data that were generated or analyzed in this study are included in this manuscript.

\section{Authors' contributions}

YJ and $\mathrm{CZ}$ conceived and designed the study. $\mathrm{CH}$ and $\mathrm{YY}$ conducted the experiments. XZ and YL performed the statistical analysis; MG interpreted the statistical analysis, reviewed and made final approval of the version to be published. All authors read and approved the manuscript.

\section{Ethics approval and consent to participate}

Not applicable.

\section{Consent for publication}

Not applicable.

\section{Competing interests}

The authors declare that they have no competing interests.

\section{References}

1. Siegel RL, Miller KD and Jemal A: Cancer statistics. CA Cancer J Clin 67: 7-30, 2017.

2. Davies L and Welch HG: Increasing incidence of thyroid cancer in the United States, 1973-2002. JAMA 295: 2164-2167, 2006.

3. Tuttle RM, Haddad RI, Ball DW, Byrd D, Dickson P, Duh QY Ehya H, Haymart M, Hoh C, Hunt JP, et al: Thyroid carcinoma, version 2.2014. J Natl Compr Canc Netw 12: 1671-1680, 2014.

4. Antonelli A, Fallahi P, Ferrari SM, Carpi A, Berti P, Materazzi G, Minuto M, Guastalli M and Miccoli P: Dedifferentiated thyroid cancer: A therapeutic challenge. Biomed Pharmacother 62: 559-563, 2008

5. Schlumberger M, Brose M, Elisei R, Leboulleux S, Luster M, Pitoia F and Pacini F: Definition and management of radioactive iodine-refractory differentiated thyroid cancer. Lancet Diabetes Endocrinol 2: 356-358, 2014
6. Haddad RI, Lydiatt WM, Ball DW, Busaidy NL, Byrd D, Callender G, Dickson P, Duh QY, Ehya H, Haymart M, et al: Anaplastic thyroid carcinoma, version 2.2015. J Natl Compr Canc Netw 13: 1140-1150, 2015.

7. Xing M, Westra WH, Tufano RP, Cohen Y, Rosenbaum E, Rhoden KJ, Carson KA, Vasko V, Larin A, Tallini G, et al: BRAF mutation predicts a poorer clinical prognosis for papillary thyroid cancer. J Clin Endocrinol Metab 90: 6373-6379, 2005.

8. Durante C, Haddy N, Baudin E, Leboulleux S, Hartl D, Travagli JP, Caillou B, Ricard M, Lumbroso JD, De Vathaire F and Schlumberger M: Long-term outcome of 444 patients with distant metastases from papillary and follicular thyroid carcinoma: Benefits and limits of radioiodine therapy. J Clin Endocrinol Metab 91: 2892-2899, 2006.

9. Davies H, Bignell GR, Cox C, Stephens P, Edkins S, Clegg S, Teague J, Woffendin H, Garnett MJ, Bottomley W, et al: Mutations in the BRAF gene in human cancer. Nature 417: 949-954, 2002.

10. McCubrey JA, Steelman LS, Chappell WH, Abrams SL, Wong EW, Chang F, Lehmann B, Terrian DM, Milella M, Tafuri A, et al: Roles of the Raf/MEK/ERK pathway in cell growth, malignant transformation and drug resistance. Biochim Biophys Acta 1773: 1263-1284, 2007.

11. Garnett MJ and Marais R: Guilty as charged: B-RAF is a human oncogene. Cancer Cell 6: 313-319, 2004.

12. Tsai J, Lee JT, Wang W, Zhang J, Cho H, Mamo S, Bremer R, Gillette S, Kong J, Haass NK, et al: Discovery of a selective inhibitor of oncogenic B-Raf kinase with potent antimelanoma activity. Proc Natl Acad Sci USA 105: 3041-3046, 2008.

13. Kim KH, Kang DW, Kim SH, Seong IO and Kang DY: Mutations of the BRAF gene in papillary thyroid carcinoma in a Korean population. Yonsei Med J 45: 818-821, 2004.

14. Namba H, Nakashima M, Hayashi T, Hayashida N, Maeda S, Rogounovitch TI, Ohtsuru A, Saenko VA, Kanematsu T and Yamashita S: Clinical implication of hot spot BRAF mutation, V599E, in papillary thyroid cancers. J Clin Endocrinol Metab 88: 4393-4397, 2003.

15. Xing M: BRAF mutation in thyroid cancer. Endocr Relat Cancer 12: 245-262, 2005.

16. Sherman SI, Angelos P, Ball DW, Beenken SW, Byrd D, Clark OH, Daniels GH, Dilawari RA, Ehya H, Farrar WB, et al: Thyroid carcinoma. J Natl Compr Canc Netw 3: 404-457, 2005.

17. DeGroot LJ, Kaplan EL, McCormick M and Straus FH: Natural history, treatment, and course of papillary thyroid carcinoma. J Clin Endocrinol Metab 71: 414-424, 1990.

18. Mazzaferri EL and Kloos RT: Clinical review 128: Current approaches to primary therapy for papillary and follicular thyroid cancer. J Clin Endocrinol Metab 86: 1447-1463, 2001.

19. Sherman SI, Brierley JD, Sperling M, Ain KB, Bigos ST, Cooper DS, Haugen BR, Ho M, Klein I, Ladenson PW, et al: Prospective multicenter study of thyroid carcinoma treatment: Initial analysis of staging and outcome. National thyroid cancer treatment cooperative study registry group. Cancer 83: 1012-1021, 1998.

20. Tanaka K, Sonoo H, Hirono M, Ohkubo S, Nomura T, Ikeda M, Nakajima K and Kurebayashi J: Retrospective analysis of predictive factors for recurrence after curatively resected papillary thyroid carcinoma. Surg Today 35: 714-719, 2005.

21. Mazzaferri EL and Jhiang SM: Long-term impact of initial surgical and medical therapy on papillary and follicular thyroid cancer. Am J Med 97: 418-428, 1994.

22. Lin KL, Wang OC, Zhang XH, Dai XX, Hu XQ and Qu JM: The BRAF mutation is predictive of aggressive clinicopathological characteristics in papillary thyroid microcarcinoma. Ann Surg Oncol 17: 3294-3300, 2010.

23. Lee X, Gao M, Ji Y, Yu Y, Feng Y, Li Y, Zhang Y, Cheng W and Zhao W: Analysis of differential BRAF(V600E) mutational status in high aggressive papillary thyroid microcarcinoma. Ann Surg Oncol 16: 240-245, 2009.

24. Brose MS, Cabanillas ME, Cohen EEW, Wirth L, Sherman SI, Riehl T, Yue H and Sherman E: An open label, multi-center phase 2 study of the BRAF inhibitor vemurafenib in patients with metastatic or unresectable papillary thyroid cancer (PTC) positive for the BRAF V600 mutation and resistant to radioactive iodine (NCT01286753, NO25530). Eur J Cancer 49 (Suppl): S13, 2013.

25. Dadu R, Shah K, Busaidy NL, Waguespack SG, Habra MA, Ying AK, Hu MI, Bassett R, Jimenez C, Sherman SI and Cabanillas ME: Efficacy and tolerability of vemurafenib in patients with BRAF(V600E)-positive papillary thyroid cancer: M.D. Anderson cancer center off label experience. J Clin Endocrinol Metab 100: E77-E81, 2015. 
26. Falchook GS, Millward M, Hong D, Naing A, Piha-Paul S, Waguespack SG, Cabanillas ME, Sherman SI, Ma B, Curtis M, et al: BRAF inhibitor dabrafenib in patients with metastatic BRAF-mutant thyroid cancer. Thyroid 25: 71-77, 2015.

27. Murphy DA, Makonnen S, Lassoued W, Feldman MD, Carter C and Lee WM: Inhibition of tumor endothelial ERK activation, angiogenesis, and tumor growth by sorafenib (BAY43-9006). Am J Pathol 169: 1875-1885, 2006.

28. Lyons JF, Wilhelm S, Hibner B and Bollag G: Discovery of a novel Raf kinase inhibitor. Endocr Relat Cancer 8: 219-225, 2001

29. Sosman JA, Kim KB, Schuchter L, Gonzalez R, Pavlick AC, Weber JS, McArthur GA, Hutson TE, Moschos SJ, Flaherty KT, et al: Survival in BRAF V600-mutant advanced melanoma treated with vemurafenib. N Engl J Med 366: 707-714, 2012.

30. Hyman DM, Puzanov I, Subbiah V, Faris JE, Chau I, Blay JY, Wolf J, Raje NS, Diamond EL, Hollebecque A, et al: Vemurafenib in multiple nonmelanoma cancers with BRAF V600 mutations. N Engl J Med 373: 726-736, 2015.

31. Montero-Conde C, Ruiz-Llorente S, Dominguez JM, Knauf JA Viale A, Sherman EJ, Ryder M, Ghossein RA, Rosen N and Fagin JA: Relief of feedback inhibition of HER3 transcription by RAF and MEK inhibitors attenuates their antitumor effects in BRAF-mutant thyroid carcinomas. Cancer Discov 3: 520-533, 2013.

32. Prahallad A, Sun C, Huang S, Di Nicolantonio F, Salazar R, Zecchin D, Beijersbergen RL, Bardelli A and Bernards R: Unresponsiveness of colon cancer to BRAF(V600E) inhibition through feedback activation of EGFR. Nature 483: 100-103, 2012.
33. Ribeiro FR, Meireles AM, Rocha AS and Teixeira MR: Conventional and molecular cytogenetics of human non-medullary thyroid carcinoma: Characterization of eight cell line models and review of the literature on clinical samples. BMC Cancer 8: 371, 2008.

34. Mercer KE and Pritchard CA: Raf proteins and cancer: B-Raf is identified as a mutational target. Biochim Biophys Acta 1653: 25-40, 2003.

35. Baitei EY, Zou M, Al-Mohanna F, Collison K, Alzahrani AS, Farid NR, Meyer B and Shi Y: Aberrant BRAF splicing as an alternative mechanism for oncogenic B-Raf activation in thyroid carcinoma. J Pathol 217: 707-715, 2009.

36. Byeon HK, Na HJ, Yang YJ, Kwon HJ, Chang JW, Ban MJ, Kim WS, Shin DY, Lee EJ, Koh YW, et al: c-Met-mediated reactivation of $\mathrm{PI} 3 \mathrm{~K} / \mathrm{AKT}$ signaling contributes to insensitivity of BRAF(V600E) mutant thyroid cancer to BRAF inhibition. Mol Carcinog 55: 1678-1687, 2016.

37. Sos ML,Levin RS, Gordan JD, Oses-Prieto JA, Webber JT, Salt M, Hann B, Burlingame AL, McCormick F, Bandyopadhyay S and Shokat KM: Oncogene mimicry as a mechanism of primary resistance to BRAF inhibitors. Cell Rep 8: 1037-1048, 2014.

38. Frasca F, Vella V, Nicolosi ML, Messina RL, Gianì F, Lotta S, Vigneri P, Regalbuto C and Vigneri R: Thyroid cancer cell resistance to gefitinib depends on the constitutive oncogenic activation of the ERK pathway. J Clin Endocrinol Metab 98: 2502-2512, 2013.

39. Danysh BP, Rieger EY, Sinha DK, Evers CV, Cote GJ, Cabanillas ME and Hofmann MC: Long-term vemurafenib treatment drives inhibitor resistance through a spontaneous KRAS G12D mutation in a BRAF V600E papillary thyroid carcinoma model. Oncotarget 7: 30907-30923, 2016. 